\title{
PENINGKATAN KOPING KELUARGA PASIEN SKIZOFRENIA MELALUI INTERVENSI MINDFULNESS
}

\author{
Irene Febriany Mamo Kitu, Meidiana Dwidiyanti, Diyan Yuli Wijayanti \\ Universitas Diponegoro Semarang, Jl Prof Soedarto Semarang \\ Email: ines.kitu@gmail.com
}

\begin{abstract}
ABSTRAK
Keluarga mempunyai beban yang besar dalam merawat anggota keluarga yang mengalami Skizofrenia, dimana stigma yang keliru dari masyarakat menjadi stresor tambahan bagi keluarga. Dalam merawat anggota keluarga yang mengalami Skizofrenia, keluarga memerlukan koping yang efektif sehingga perawatan yang diberikan dapat optimal. Salah satu cara yang dapat dilakukan oleh keluarga adalah dengan meningkatkan kesadaran dan perhatian melalui intervensi mindfulness. Tujuan untuk mengetahui pengaruh intervensi mindfulness terhadap tingkat koping keluarga pasien Skizofrenia. Penelitian ini menggunakan desain quasi experiment dengan rancangan pre-post test with control grup design. Teknik sampling yang digunakan adalah purposive sampling dengan populasi sebanyak 50 keluarga yang terbagi atas 25 kelompok intervensi dan 25 kelompok control, dengan menggunakan instrument Ways Of Coping. Hasil ditunjukkan adanya pengaruh terhadap tingkat koping keluarga pasien Skizofrenia sesudah diberikan intervensi mindfulness dengan nilai $p=0,000$. Pemberian intervensi mindfulness dapat membantu keluarga meningkatkan koping yang efektif dengan cara lebih fokus dan menerima keadaan yang terjadi tanpa menghakiminya, sehingga pemberian pelayanan tidak hanya berfokus kepada pasien saja tetapi juga mencakup keluarga pasien.
\end{abstract}

Kata Kunci: koping keluarga; skizofrenia; mindfulness

\section{IMPROVEMENT OF SCIZOFRENIA PATIENTS' FAMILY THROUGH MINDFULNESS INTERVENTION}

\begin{abstract}
ABSTRAK
The family has a big burden in caring for family members who experience Schizophrenia, where the wrong stigma from the community becomes an additional stressor for the family. In treating family members who have Schizophrenia, families need effective coping so that the care provided can be optimal. One way that families can do is to increase awareness and attention through mindfulness interventions. This study was to determine the effect of mindfulness interventions on the level of coping in families of Schizophrenia patients. This research used a quasi-experimental design with a pre-post-test with control group design. The sampling technique used was purposive sampling with a population of 50 families divided into 25 intervention groups and 25 control groups. The study was conducted on 50 families using the Ways of Coping instrument. Results: There was an influence on the level of coping in Schizophrenia family after mindfulness intervention with $p=0,000$. Conclusion: Providing mindfulness interventions can help families improve effective coping by focusing more and accepting the circumstances that occur without judging them, so that service delivery does not only focus on the patient but also includes the patient's family
\end{abstract}

Keywords: family coping; schizophrenia; mindfulness 


\section{LATAR BELAKANG}

Keluarga merupakan sumber dukungan yang berarti bagi anggota keluarga yang mengalami gangguan jiwa karena keluarga mempunyai peran penting dalam memberikan perawatan dan kasih sayang (Rahmani, 2019). Selain itu, pasien gangguan jiwa membutuhkan bantuan dari keluarga dalam beradaptasi dengan lingkungan sekitar dimana adanya perubahan-perubahan kondisi dan sikap dari masyarakat dalam menerima pasien gangguan jiwa (Lestari, 2016). Kebutuhan psikologis dimana pasien gangguan jiwa membutuhkan pengakuan dan perhatian yang tulus dari keluarga akan sangat membantu proses penyembuhan dari pasien gangguan jiwa itu sendiri (Suryaningrum, 2013).

Keluarga yang mempunyai anggota keluarga yang menderita gangguan jiwa beresiko mengalami stres tingkat sedang dengan hasil penelitian sebesar 66,7\% (Mubin, 2013). Data Riset Kesehatan Dasar (Riskesdas) menyebutkan bahwa penderita gangguan jiwa ringan di Indonesia sebanyak 2,36 juta, gangguan jiwa berat sebesar 0,17 juta. Data Riskesdas Jawa Tengah menempati urutan ke-5 sebagai provinsi yang memiliki jumlah penderita gangguan jiwa tertinggi di Indonesia, dimana prevalensi Riskesdas 2018 terdapat sebesar 8,7\% penderita skizofrenia di Rumah Sakit Jiwa (Riskesdas, 2018). Data rekam medis di Rumah Sakit Jiwa Dr. Amino Gondohutomo Provinsi Jawa Tengah menyebutkan pada tahun 2018 terdapat 3.171 (64\%) merupakan pasien skizofrenia (Rekam Medis Rumah Sakit Jiwa, 2018).

Penilaian dan stigma yang salah dari masyarakat sekitar tentang pasien gangguan jiwa yang merupakan aib menyebabkan keluarga merasa malu dan sulit untuk menerima keadaan anggota keluarga yang mengalami gangguan jiwa (Taufik, 2014). Permasalahan dan konflik juga dapat terjadi antara anggota keluarga, dimana antara anggota keluarga akan saling menyalahkan terhadap keadaan yang terjadi. Biaya yang harus ditanggung oleh keluarga selama proses pengobatan dan pemulihan serta waktu yang digunakan untuk merawat anggota keluarga yang mengalami gangguan jiwa dapat menjadi stresor yang menyebabkan keluarga merasa lelah baik secara fisik maupun psikis (Pharoah, 2014).

Koping merupakan suatu proses bagaimana individu merespon dan bertindak saat keadaan di sekitar tidak sesuai dengan harapan yang dapat menyebabkan stress (Rahmani, 2019). Beban dan kesulitan yang dihadapi oleh keluarga mengharuskan keluarga memiliki strategi yang dapat membantu keluarga menghadapi situasi yang terjadi dengan memodifikasi dan fleksibiltas peran dalam keluarga (Rahman, 2016). Latihan kesadaran atau yang saat ini dikenal sebagai mindfulness telah teruji dalam membantu meningkatkan kemampuan menghadapi masalah melalui penerimaan dan reflleksi (Sutini, 2014).

Mindfulness merupakan tradisi meditasi Budha yang berfokus pada latihan perhatian untuk menumbuhkan kemampuan dalam menanggapi masalah dengan penuh perhatian sehingga dapat meningkatkan kesehatan psikologis dan mengurangi gejala stres (Baer, 2012). Perhatian dan kesadaran dengan memperhatikan pengalaman atau keadaan yang terjadi saat ini memiliki manfaat untuk kesejahteraan dan kesehatan keluarga, dimana mindfulness memfasilitasi keseimbangan didalam keluarga dengan tetap memperhatikan kondisi psikologis dan sosial apa yang mendukung dan menghambat kemampuan keluarga (Hulsheger, 2018). Penelitian sebelumnya terkait intervensi mindfulness dilakukan pada pasien dengan masalah penyakit kronis, family caregivers dengan demensia, perawatan kesehatan umum dan belum ada penelitian sebelumnya tentang penerapan intervensi mindfulness terhadap koping keluarga. Berdasarkan data diatas penelitian ini dilakukan untuk mengetahui pengaruh intervensi mindfulness terhadap tingkat koping keluarga pasien Skizofrenia.

\section{METODE}

Penelitian ini menggunakan desain quasiexperiment dengan model rancangan pre-post test with control grup design. Sampel dalam penelitian ini diambil berdasarkan perhitungan effect size dengan power 80 yaitu sebanyak 50 keluarga yang 
terbagi atas 25 kelompok intervensi dan 25 kelompok kontrol. Penelitian dilaksanakan di RSJD Dr. Amino Gondohutomo Provinsi Jawa Tengah.Teknik sampling yang digunakan dalam pengambilan sampel adalah purposive sampling dengan menetapkan ciri-ciri khusus sesuai dengan tujuan penelitian dalam pengambilan sampel. Instrumen yang digunakan yaitu kuesioner Ways of Coping (WOC)yang telah dimodifikasi dan terdiri atas 22 pertanyaan untuk mengukur tingkat koping keluarga.

\section{HASIL}

Tabel 1 Distribusi Frekuensi Karakteristik Keluarga Pasien Skizofrenia

\begin{tabular}{|c|c|c|c|c|c|}
\hline \multirow{3}{*}{ Variabel } & \multicolumn{4}{|c|}{ Kelompok } & \multirow{3}{*}{$p$} \\
\hline & \multicolumn{2}{|c|}{ Intervensi (n=25) } & \multicolumn{2}{|c|}{ Kontrol $(n=25)$} & \\
\hline & $f$ & $\%$ & $f$ & $\%$ & \\
\hline \multicolumn{5}{|l|}{ Usia } & \multirow{4}{*}{0,405} \\
\hline Dewasa Muda & 10 & 40,0 & 6 & 24,0 & \\
\hline Dewasa Madya & 13 & 52,0 & 15 & 60,0 & \\
\hline Dewasa Akhir & 2 & 8,0 & 4 & 16,0 & \\
\hline \multicolumn{5}{|l|}{ Jenis Kelamin } & \multirow{3}{*}{1,000} \\
\hline Laki-laki & 12 & 48,0 & 11 & 44,0 & \\
\hline Perempuan & 13 & 52,0 & 14 & 56,0 & \\
\hline \multicolumn{5}{|l|}{ Pendidikan Terakhir } & \multirow{5}{*}{0,081} \\
\hline SD & 6 & 24,0 & 15 & 60,0 & \\
\hline SMP & 8 & 32,0 & 4 & 16,0 & \\
\hline SMA & 8 & 32,0 & 4 & 16,0 & \\
\hline S1 & 3 & 12,0 & 2 & 8,0 & \\
\hline \multicolumn{5}{|l|}{ Pekerjaan } & \multirow{3}{*}{0,72} \\
\hline Bekerja & 19 & 76,0 & 21 & 84,0 & \\
\hline Tidak Bekerja & 6 & 24,0 & 4 & 16,0 & \\
\hline \multicolumn{5}{|c|}{ Hubungan dalam Keluarga } & \multirow{4}{*}{0,35} \\
\hline Orang tua & 14 & 56,0 & 15 & 60,0 & \\
\hline Suami/lstri & 4 & 16,0 & 1 & 4,0 & \\
\hline Lain-lain & 7 & 28,0 & 15 & 60,0 & \\
\hline \multicolumn{5}{|l|}{ Lama Sakit } & \multirow{4}{*}{0,400} \\
\hline$<1$ tahun & 14 & 56,0 & 18 & 72,0 & \\
\hline 1-10 tahun & 8 & 32,0 & 6 & 24,0 & \\
\hline$>10$ tahun & 3 & 12,0 & 1 & 4,0 & \\
\hline
\end{tabular}

Dari tabel 1 menunjukkan bahwa pada kelompok sakit < 1 tahun sebanyak 14 orang (56,0\%), intervensi, mayoritas keluarga berusia madya sedangkan pada kelompok kontrol mayoritas sebanyak 13 orang $(52,0 \%)$, berjenis kelamin perempuan sebanyak 13 orang $(52,0 \%)$, tingkat pendidikan SMP dan SMA sebanyak masingmasing 8 orang $(32,0 \%)$, bekerja sebanyak 19 orang $(76,0 \%)$, hubungan dalam keluarga adalah orang tua sebanyak 14 orang $(56,0 \%)$ dan lama keluarga berusia madya sebanyak 15 orang $(60,0)$, berjenis kelamin perempuan sebanyak 14 orang $(56,0)$, tingkat pendidikan SD sebanyak 15 orang $(60,0)$, bekerja sebanyak 21 orang $(84,0)$, hubungan dalam keluarga adalah orang tua dan lain-lain sebanyak masing-masing 15 orang $(60,0)$ dan lama sakit < 1 tahun sebanyak 18 orang $(72,0)$. 
Tabel 2 Distribusi frekuensi tingkat koping keluarga Pasien Skizofrenia sebelum dilakukan Intervensi mindfulness pada kelompok intervensi dan kelompok kontrol

\begin{tabular}{lcccc}
\hline \multicolumn{1}{c}{ Koping Keluarga } & \multicolumn{2}{c}{ Intervensi } & \multicolumn{2}{c}{ Kontrol } \\
& $\mathrm{f}$ & $\%$ & $\mathrm{f}$ & $\%$ \\
\hline Sebelum Intervensi & & & & \\
Efektif & 0 & 0 & 1 & 4,0 \\
Tidak Efektif & 25 & 100,0 & 24 & 96,0 \\
\hline Total & 25 & 100,0 & 25 & 100,0 \\
\hline
\end{tabular}

Dari tabel 2 menunjukkan bahwa keluarga pada kelompok intervensi sebelum dilakukan intervensi mindfulness berada pada tingkat koping tidak efektif sebanyak 25 orang $(100,00 \%)$ danpada kelompok kontrol tingkat koping tidak efektif sebanyak 24 orang $(96,0 \%)$.

Tabel 3 Distribusi frekuensi tingkat koping keluarga Pasien Skizofrenia sesudah dilakukan intervensi Mindfulness pada kelompok intervensi dan kelompok kontrol

\begin{tabular}{lcccc}
\hline \multicolumn{1}{c}{ Koping Keluarga } & \multicolumn{2}{c}{ Intervensi } & \multicolumn{2}{c}{ Kontrol } \\
& $\mathrm{F}$ & $\%$ & $\mathrm{~F}$ & $\%$ \\
\hline Sesudah Intervensi & & & & \\
Efektif & 22 & 88,0 & 4 & 16,0 \\
Tidak Efektif & 3 & 12,0 & 21 & 84,0 \\
Total & 25 & 100,00 & 25 & 100,00 \\
\hline
\end{tabular}

Dari tabel 3 menunjukkan bahwa keluarga pada kelompok intervensisesudah diberikan intervensi mindfulness berada pada tingkat koping efektif sebanyak 22 orang $(88,0 \%)$ dan pada kelompok kontrol sesudah post-test berada pada tingkat koping tidak efektif sebanyak 21 orang $(84,0 \%)$

Tabel 4 Pengaruh intervensi Mindfulness terhadap tingkat koping keluarga Pasien Skizofrenia antara kelompok intervensi dan kelompok kontrol

\begin{tabular}{lcccccc}
\hline & & \multicolumn{2}{c}{ Intervensi } & \multicolumn{2}{c}{ Kontrol } & \multirow{2}{*}{$p$} \\
\cline { 3 - 6 } & & Mean \pm SD & Min-Max & Mean \pm SD & Min-Max & \\
\hline Tingkat Koping & Sebelum & $27,92 \pm 6,66$ & $15-40$ & $26,68 \pm 8,83$ & $15-45$ & 0,578 \\
& Sesudah & $45,00 \pm 2,42$ & $14-52$ & $31,96 \pm 10,84$ & $14-55$ & 0,000 \\
\hline
\end{tabular}

Dari tabel 4 menunjukkan bahwa terdapat perubahan tingkat koping sebelum diberikan intervensi mindfulness dengan nilai $p=0,578$ dan sesudah diberikan intervensi terdapat peningkatan koping dengan nilai $p=0,000$

\section{PEMBAHASAN}

Keluarga memiliki peran yang besar dalam merawat anggota keluarga yang mengalami Skizofrenia karena keluarga harus memberikan dukungan dan perhatian, sehingga dampak negatif tidak hanya dirasakan oleh anggota keluarga yang mengalami Skizofrenia saja tetapi juga oleh keluarga dimana keluarga mengalami stres dan gejala depresi (Bademli, 2014 ; Tan, 2012).Hal ini serupa dengan hasil yang ditemukan oleh
Rahmani, et al (2015) bahwa sebesar 54,22\% keluarga mempunyai koping yang tidak efektif dalam menghadapi anggota keluarga dengan Skizofrenia (Rahmani, 2015). Hasil data awal yang didapatkan dalam penelitian ini menunjukkan bahwa tingkat koping keluarga sebelum diberikan terapi mindfulness pada kelompok intervensi dan kelompok kontrol memiliki koping yang tidak efektif, yaitu sebanyak $25(100,00 \%)$ pada kelompok 
intervensi dan sebanyak $24 \quad(96,0 \%)$ pada kelompok kontrol.

Keluarga harus menghadapi diskriminasi sosial dari masyarakat, sehingga koping merupakan bagian penting dimana usia, lama sakit dan hubungan dalam keluarga juga mempengaruhi keluarga dalam membantu proses pemulihan anggota keluarga yang mengalami skizofrenia (Iseselo, 2016). Faktor lain yang menyebabkan tidak efektifnya koping keluarga karena kurangnya pengetahuan keluarga akan penyakit pasien dan penanganannya, stresor yang dihadapi dalam keluarga, serta biaya pengobatan yang harus dikeluarkan oleh keluarga (Lyu, 2019). Hasil penelitian menunjukkan bahwa $26,7 \%$ keluarga mengalami kesulitan dalam beraktivitas, $24,7 \%$ keluarga mengalami beban secara sosial, 31,3\% keluarga merasa tertekan dengan situasi yang terjadi, 33,3\% keluarga merasa kecewa dengan stigma negatif yang didapat dari masyarakat dan hanya $14,7 \%$ keluarga yang mencari bantuan dari petugas kesehatan (Bademli, 2014). Penelitian lain menyebutkan bahwa sebesar 90,5\% beban yang dihadapi oleh keluarga karena beban keuangan (Shamsei, 2015).

Tingkat stres dan beban yang dihadapi oleh keluarga dipengaruhi oleh strategi koping yang digunakan oleh keluarga, dimana keluarga yang memiliki anggota keluarga skizofrenia 22\% mengalami stres ringan, $56 \%$ mengalami stres sedang dan 22\% mengalami stres berat, sehingga keluarga perlu belajar untuk mengatasi kesulitan, berkolaborasi dengan tenaga kesehatan agar dapat mempertahankan fungsi keluarga dan mengembangkan kemampuan koping yang dimiliki (Emine, 2014). Koping memungkinkan keluarga untuk mengumpulkan informasi, mengendalikan masalah dan juga sebagai respon saat mengatasi masalah, sehingga penggunaan koping yang baik dapat membantu keluarga untuk meringankan beban yang dialami (Rexhaj, 2013). Hal ini didukung oleh hasil yang ditemukan bahwa 17,4\% keluarga tahu apa yang harus dilakukan dalam menghadapi anggota keluarga yang mengalami masalah gangguan jiwa, seperti mencari dukungan sosial dan pemecahan masalah (Madathumkovilakath, 2018). Tekanan yang dihadapi oleh keluarga dapat diatasi dengan merubah persepsi keluarga terhadap stresor yang ada, lalu berusaha meningkatkan sumber daya pribadi yang dimiliki dengan cara menikmati proses yang terjadi. Keterampilan keluarga dalam mengatur emosi dapat membantu keluarga mengurangi ketegangan dan kecemasan akan masalah yang dihadapi, sehingga pada saat ketegangan dan kecemasan berkurang akan meningkatkan kemampuan keluarga dalam mentoleransi emosi dan meningkatkan emosi positif (Greenberg, 2006).

Penelitian lain menyebutkan bahwa terdapat peningkatan yang signifikan terhadap latihan regulasi emosi pada keluarga dengan nilai $p=$ 0,043 dan nilai rata-rata kelompok intervensi $(13,60)$ di bandingkan nilai rata-rata kelompok kontrol $(-0,20)$ (Andriani, 2017). Penelitian sebelumnya menunjukkan bahwa intervensi mindfulness secara signifikan dapat meningkatkan kesadaran keluarga dalam membantu anggota keluarga yang mengalami gangguan jiwa sebesar 85\% pada kelompok intervensi (Stjernswärd, 2018). Pentingnya mindfulness terhadap kemampuan keluarga untuk tidak menghakimi anggota keluarga yang mengalami gangguan jiwa terkait dengan kesehatan mental yang baik dari keluarga tersebut dan didukung dengan hasil yang mengatakan bahwa intervensi mindfulness mampu mengurangi stres yang dialami keluarga dengan hasil $p<0,001$ (Hwang, 2013).

Intervensi mindfulness yang diberikan kepada keluarga dengan memanfaatkan strategi kognitif dan perilaku mampu mengurangi konflik, meningkatkan keterampilan dalam berkomunikasi dan meningkatkan efikasi diri dengan nilai $p=$ 0,001 (Weinstein, 2009). Hal ini terbukti dengan adanya kemampuan koping yang efektif dalam membantu keluarga mengurangi kesulitan serta meningkatkan kesejahteraan dalam menghadapi situasi yang penuh tekanan serta penerimaan hal positif dari masalah yang terjadi (Rayan, 2016). Beban yang dihadapi oleh keluarga berhubungan 
dengan koping yang dimiliki oleh keluarga itu sendiri, dimana saat keluarga menghadapi masalah, keluarga akan melakukan penilaian kembali dalam merasakan emosi positif dari masalah yang terjadi, sehingga intervensi mindfulness dapat diterapkan untuk meningkatkan penilaian kembali secara positif (Garland, 2009).

\section{KESIMPULAN DAN SARAN}

Hasil penelitian dapat disimpulkan bahwa terdapat pengaruh terhadap tingkat koping keluarga setelah diberikan intervensi mindfulness dengan nilai $p=$ 0,000 . Diharapkan terapi mindfulness dapat digunakan oleh penyedia layanan kesehatan dalam membantu keluarga meningkatkan koping yang efektif sehingga pelayanan yang diberikan tidak hanya berfokus kepada pasien saja tetapi juga kepada keluarga.

\section{REFFERENSI}

Andriani RADR, Afiatin T, Sulistyarini RI. (2017). Efektivitas pelatihan regulasi emosi untuk meningkatkan resiliensi caregiver-keluarga pasien skizofrenia. 2017 vol.9 no.2

Bademli K, Çetinkaya Z. (2014). Archives of psychiatric nursing effects of a family-tofamily support program on the mental health and coping strategies of caregivers of adults with mental illness: A Randomized Controlled Study.2014;28(6):392-8

Baer RA, Carmody J, Hunsinger M. (2012) Weekly Change in Mindfulness and Perceived Stress in a Mindfulness-Based Stress Reduction Program. Journal of Clinical Psychology, Vol. 68(7).

Emine E, Do S. Archives of psychiatric nursing the effect of a brief cognitive behavioural stress management programme on mental status , coping with stress attitude and caregiver burden while caring for schizophrenic patients. 2017;(September 2016)

Garland E, Gaylord S, Park J. The role of mindfulness in positive reappraisal. 2009;5(1):37-44

Greenberg LS, Pascual-Leone A. Emotion in psychotherapy: a practice-friendly research review. 2006; 62(5), 611-630

Hwang YS, Kearney P. (2013). A systematic review of mindfulness intervention for individuals with developmental disabilities: long-term practice and long lasting effects; 34,314-26

Hülsheger UR, Walkowiak A, Thommes MS. (2018). How Can Mindfulness be Promoted? Workload and Recovery Experiences as Antecedents of Daily Fluctuations in Mindfulness. Journal of Occupational and Organizational Psychologi; 91, 261-284

Iseselo MK, Kajula L, Yahya-malima KI. (2016). The psychosocial problems of families caring for relatives with mental illnesses and their coping strategies: a qualitative urban based study in Dar es Salaam;1-12

Lestari DR, Karmila, Herawati. (2016). Dukungan keluarga dengan kepatuhan minum obat pada pasien gangguan jiwa di wilayah kerja puskesmas banjarbaru. Dunia Keperawatan; Volume 4:88-92.

Lyu Q, Zhang M. (2019). A qualitative study exploring coping strategies in Chinese families during children ' $s$ hospitalization for cancer treatment. J Pediatr Nurs [Internet].

Madathumkovilakath NB, Kizhakkeppattu S, Thekekunnath S, Kazhungil F. (2018). Coping strategies of caregivers towards aggressive behaviors of persons with severe mental illness. Asian J Psychiatr [Internet].

Marguerite S, Laurent B, Marine A, Tanguy L, Karine B, Pascal A, et al. (2017). Actorpartner interdependence analysis in depressed patient-caregiver dyads: In fluence of emotional intelligence and coping strategies on anxiety and depression;(April):0-1

Mubin MF, Andriani T. (2013). Gambaran tingkat stres pada keluarga yang memiliki penderita gangguan jiwa di RSUD Dr. H. Soewondo Kendal;299-302

Pharoah F, Mari J, Rathbone J, Wong W. Family Intervention For Scihozophrenia. Eur PMC Funders Gr. 2014;(12)

Rahmani F, Ranjbar F, Hosseinzadeh M, Razavi 
SS. (2019). Coping strategies of family caregivers of patients with schizophrenia in Iran: A cross-sectional survey. Int J Nurs Sci [Internet].

Rahmani F, Ranjbar F, Ebrahimi H, Hosseinzadeh M. (2015). The effects of group psychoeducational programme on attitude toward mental illness in families of patients with schizophrenia; 4(3):243-51

Rayan A, Ahmad M. (2016). Research in Developmental Disabilities Effectiveness of mindfulness-based interventions on quality of life and positive reappraisal coping among parents of children with autism spectrum disorder; 55:185-96

Rexhaj S, Python NV, Morin D, Bonsack C, Favrod J. (2013). Correlational study: illness representations and coping styles in caregivers for individuals with schizophrenia. Ann Gen Psychiatry [Internet]; 12(1):1.

Romadhani RK, Hadjam MNR. (2017). Intervensi Berbasis Mindfulness untuk Menurunkan Stres pada Orang Tua. 2017;3(1):23-37
Shamsaei F. Burden on Family Caregivers Caring for Patients with Schizophrenia; 239-45

Stjernswärd S, Hansson L. (2018). Effectiveness and usability of a web-based mindfulness intervention for caregivers of people with mental or somatic illness .A randomized controlled trial; 12(March):46-56

Suryaningrum S, Wardani IY. 92013). Hubungan Antara Beban Keluarga Dengan Kemampuan Keluarga Merawat Pasien Perilaku Kekerasan Di Poliklinik Rumah Sakit Marzoeki Mahdi Bogor. J Keperawatan Jiwa; 1(2)

Tan SCH, Yeoh AL, Choo IBK, Huang APH, Ong $\mathrm{SH}$, Ismail H. (2012). Burden and coping strategies experienced by caregivers of persons with schizophrenia in the community; 2410-8

Taufik Y, Mamnu'ah. (2014). Hubungan Dukungan Keluarga Dengan Tingkat Kekambuhan Pada Pasien Skizofrenia Di Poliklinik Rumah Sakit Jiwa Grhasia DIY; 1-15.

Weinstein N, Brown KW, Ryan RM. A multi-method examination of the effects of mindfulness on stress attribution, coping, and emotional wellbeing. 2009;43(3):374-85 